\title{
The bicycle and the dream of a sustainable city: An explorative comparison of the image of bicycles in the mass-media and the general public
}

\author{
Alessandra Rimano ${ }^{a, *}$, Maria Paola Piccini ${ }^{b}$, Paola Passafaro ${ }^{c}$, Renata Metastasio ${ }^{c}$, \\ Claudia Chiarolanza ${ }^{\mathrm{d}}$, Aurora Boison ${ }^{\mathrm{c}}$, Franco Costa ${ }^{\mathrm{C}}$ \\ ${ }^{a}$ University of Rome - La Sapienza, Department of Social Sciences and Economics, Italy \\ ${ }^{\mathrm{b}}$ Salesian Pontifical University, Faculty of Social Communication, Italy \\ ${ }^{\mathrm{c}}$ University of Rome - La Sapienza, Department of Developmental and Social Psychology, Italy \\ ${ }^{\mathrm{d}}$ University of Rome - La Sapienza, Department of Dynamic and Clinical Psychology, Italy
}

\section{A R T I C L E I N F O}

\section{Article history:}

Received 27 June 2014

Received in revised form 10 October 2014

Accepted 19 January 2015

\section{Keywords:}

Sustainable mobility

Bicycle

Mass media

Agenda setting

Travel mode choice

\begin{abstract}
A B S T R A C T
This paper explores the representation of the bicycle by comparing data from various mass media sources and the general public in Italy. In study 1, a number of commercial advertisements published on paper magazines and aired by the major TV channels, as well as 405 articles published by the major online newspapers were content analysed in order to identify the main concepts and evaluations characterising the representation of bikes in the media. In study 2, 94 Rome residents were interviewed on their beliefs regarding the pros and cons of using the bike in the city and their perceived social approval. Results showed several points of overlap between the two representations, although different themes and structures emerged as well.
\end{abstract}

(c) 2015 Elsevier Ltd. All rights reserved.

[...] the worst enemies of the bicycle in the urban areas are not cars, but longheld prejudices [...] (Bjerregaard, 1999) ${ }^{1}$

\section{Introduction}

In modern western societies, mass media are one of the many contexts in which social cultural values, beliefs and evaluations concerning relevant social objects are constructed and socially shared (e.g. Atkin, 1980; Jovchelovitch, 2001; Moscovici, 2001). For example, according to the Agenda Setting Theory (McCombs \& Shaw, 1972; Shaw, 1979), a correlation exists between what is included in (or excluded from) the content of mass media and what people tend to include in (or exclude from) the content of their knowledge, beliefs and evaluations (Andrews \& Caren, 2010). Nevertheless, the role of mass media in the diffusion of preferences or habits concerning specific travel modes still needs to be defined. In particular, little is known about the way mass media can contribute to the diffusion of alternative travel modes such as cycling. The

\footnotetext{
* Corresponding author at: University of Rome - La Sapienza, Department of Social Sciences and Economics, Italy.

${ }^{1}$ European Commissioner.
} 
present study aims to address these shortcomings by comparing the representation of the bicycle as it emerges from the mass media with people's beliefs and evaluations regarding the use of the bicycle in the city.

\subsection{The effects of mass media communication on the audience}

News media are considered as a primary source of information that can reflect and reinforce the attitudes of a community. In this sense, news media play an important "agenda setting" function as they influence what people think about (McCombs, 2005; McCombs \& Shaw, 1972) and their attitudes towards issues (Kitzinger, 2007); the higher up an issue is on the news agenda, the more likely it would be seen as important by the public. However, this is not an all-or-none phenomenon, but can entail different levels of salience and knowledge of the issue from general to more specific, depending on various intervening factors (Benton \& Frazier, 1976). Among these factors are the more passive vs. active role of the audience in relation to specific media (press, TV, internet, etc.) and the genre (news, advertisement, entertainment, etc.) of the communication (Livingstone, 1990; Losito, 2009). In this sense, paper and online press are often seen to stimulate a more active role in their audience (based on a more thorough process of information selection, interpretation and memorisation), while TV programmes, and among these, TV commercials, are often placed at the opposite end of this continuum as the audience tends to play a much more passive role. Another intervening factor concerns the audience's personal values and background. Becker and Connor (1981) found that people with different values showed different patterns of exposure to different media (TV, newspaper, magazines). Zaho (2012) found a positive correlation between altruism and the extent to which participants used various media sources (e.g. newspapers, books, internet, TV news, etc.) to collect information about some environmental issues. The empirical evidence suggests that this might be due to the different values underlying the communications produced by different sources, as people tend to select the sources and the messages that appear congruent with the values they hold. A crucial role has also been ascribed to the social and normative context (often referred to as the situation) in which the communication takes place. This has to be intended at both the macro or distal level (society and community) and the micro or proximal one (family, peers, colleagues, acquaintances, etc.). Indeed, the final interpretation and relevance attributed to a media message is typically negotiated with the people with whom the audience directly interact, or with the internalised representation of the norms accepted by such people, and in general, it is usually compared with the normative rules of the broader social categories considered relevant for that behaviour (Denham, 2004). Hence, these studies suggest the importance of investigating mass media communication that focuses on different media and taking into account aspects such as the social values and norms that they explicitly or implicitly support.

\subsection{Mass media, environmental issues and urban cycling}

Many studies have suggested a significant media agenda-setting effect for environmental issues; the public relies heavily on the media for information about the environment, and a strong correlation has been found between the media coverage of an issue and public agendas (Ader, 1995; Brondi, Armenti, Cottone, Mazzare, \& Sarrica, 2014; Holbert, Kwak, \& Shah, 2003; Sarrica, Brondi, \& Cottone, 2014; Zaho, 2012). In turn, the media's environmental agenda is highly dependent on the agendabuilding efforts of sources who provide information subsidiaries to the media to ultimately influence public and policy agendas (Curtin \& Rhodenbaugh, 2001; Gandy, 1982; Turk, 1986). In the cycling domain, a study by Rissel, Bonfiglioli, Emilsen, and Smith (2010) documented the representation of cycling in the newspapers of two Australian cities (Sydney and Melbourne). The coverage appeared to reflect the degree of development of cycling in different areas of the two cities, but the various newspapers differed substantially in terms of how they reported the stories, ranging widely from positive to negative representations. Another important aspect to notice is that the study showed a widespread use of positive framing of "cycling" as a practice, while "cyclists" were often portrayed negatively. Discussing the plausible implications of this result, the authors suggested the possibility that unfavorable news might deter people from considering cycling as a transport option. More generally, it seems plausible that the prominence and type of news coverage that cycling receives could shape public understanding of cyclists and cycling, and could affect both the uptake of cycling as a common practice and public support of the policies directed to increase its use. Because of the importance of cycling for sustainable mobility in urban contexts, further research is needed about the way in which it has been framed in the mass media in recent years. While the existing literature on media and cycling has exclusively focused on news coverage, more attention could be given to the way in which various media address this particular issue in a given context, and to its relationship with the audience's parallel opinions.

\subsection{Aims of the studies}

The general aim of the studies reported here was to compare the image of bikes (and its users) as it emerges from various types of media in Italy (study 1 ) with that derived from the individual experience of people living in a big Italian city (study 2). In other words we aimed to identify the conceptual dimensions to which the two representations were anchored and explore the overall social support towards the use of this means of transportation. In order to do this, in study 1, particular attention was dedicated to explore the main topics addressed (e.g. concepts, ideas, themes), the references to the physical (e.g. when and where) and social (e.g. work/leisure, family/peers/colleagues, 
etc.) contexts in which the bicycle was represented or mentioned, and the human values to which the messages tended to appeal. In study 2 urban residents' beliefs concerning (1) the pros and cons of using the bicycle in a big city (behavioural beliefs) and (2) the perceived social approval or disapproval of such behaviour together with the reasons associated with it (normative beliefs) were investigated.

\section{Method (study 1)}

\subsection{Units of analysis}

The three major generalist media - TV, paper press and internet - and two radically different kinds of genres - news and advertisements - were finally considered as units of analysis. The goal was to retain all of the commercial advertisements and news articles in which the bicycle was mentioned, described or visually represented, independent of the prominence or marginality of its role in the text.

Data collection started with a survey of the commercial advertisements published in the major periodicals that were issued monthly and weekly in Italy from 2006 to $2008 .^{2}$ In particular, the issues from the month of May for the monthly magazines and the issues from the third week of the month of May for the weeklies were monitored for each year. A total of 38 ads (17 from the monthlies and 21 from the weeklies) were eventually found and used in the analysis.

The whole programming aired by the major Italian TV broadcasters ${ }^{3}$ was also analysed, considering a sample-week of the month of May 2007. A total of 12,770 spots (345 non-redundant) were monitored, and 12 different spots (aired 610 times) in which the bicycle appeared in some role were identified.

A survey of the six major Italian newspapers ${ }^{4}$ and weekly magazines published in the years 2010 and 2011 was also conducted and led to the identification of a total of 30 usable articles for the study aim. A survey of the news articles published in national traditional magazines (weekly and monthly) carried out in the same period revealed almost a total absence of articles dedicated to or even marginally referring to the bicycle.

Finally, we analysed the news articles published in various Italian online newspapers ${ }^{5}$ during the five weeks between August and September 2011, and found 405 articles addressing or even just mentioning issues concerning the bicycle.

\subsection{Detection mode and data analysis}

A content analysis (Berelson, 1952; Kassarjian, 1977) procedure was used to analyse the latent and manifest content of the data collected. Content analysis is a research technique particularly suitable to analyse any integrated set of signs (or "text"), which are important as acts of communication. Texts can be of different nature (written texts, audio-visual materials, etc.) and characterised by multiple codes (linguistic, paralinguistic, iconic, gestural, etc.). The analysis leads to a series of judgements or descriptions made under specifically defined conditions by judges trained in the use of objectively defined criteria (Fearing, 1953; Krippendorff, 1980). To this aim a codebook is created and used as guideline in the analysis in order to "interview" the text. The codebook is similar to a structured questionnaire composed of a succession of items, each designed to detect the presence/absence of a particular property considered relevant to the study. Four codebooks were created ad hoc and used as guidelines to interview the (written and audio-visual) texts that were sampled. The codebooks had four thematic areas in common. The first one concerned the structural and formal aspects of the text and included items that assessed the general characteristics of the ad, TV spot or article considered (e.g. type of text, overall length, placement in the unit of the analysis, editorial choices, etc.). The second (topics and context description) referred to the topics and main themes that were addressed by the unit of analysis (topic description), as well as the physical (e.g. where/when) and social contexts (e.g. work/ school/leisure/cultural, family, etc.) to which the text referred and/or in which the event discussed/represented took place (context description). This area also included items aimed at assessing the presence/absence of a cyclist as a main character (cyclist description) together with their corresponding features (e.g. age, gender, behaviour, social interaction, etc.). The third area (communication analysis) concerned the way in which the topics were addressed in terms of the characteristics of the source of the text (e.g. expert, non-expert), the level of depth with which the issue was addressed (unsatisfactory/satisfactory/good/excellent), the specific articulation of the discourse (e.g. wide/limited, explicit/hermetic, detailed/generic, etc.) and the apparent goals of the message (e.g. identifying a problem with or without proposing solutions, orienting/changing attitudes/values, etc). The fourth area (attitudes and values) investigated possible references to the components of attitudes as they are known in social psychology (cognitive: providing information; emotional: eliciting emotions; conative: representing/suggesting actions) (Eagly \& Chaiken, 1993) and to universal human values (Schwartz, 1992). Following Stern, Dietz, and Guagnano (1998), these were namely: egoistic values, altruistic values, biospheric values, traditional values and openness to change.

The codebooks differed in the way that the items were formulated in relation to the peculiarity of each context unit (TV $v s$. traditional and online press) and of the corresponding unit of analysis (advertising vs. article and online press). For

\footnotetext{
${ }^{2}$ The list of the (monthly and weekly) periodicals considered is available from the authors on request.

${ }^{3}$ The TV broadcasters considered were Rai1, Rai2, Rai3, Rete 4, Canale 5, Italia 1.

${ }^{4}$ These were namely Il corriere della sera, La repubblica, L'Unità, La Stampa, Il fatto quotidiano, Il manifesto.

${ }^{5}$ The list of the sources and the codebooks are available from the authors on request.
} 
example, coding format for (TV and press) advertisements aimed at detecting the (one) characterising topic of each ad considered, while for (online and traditional) news articles, multiple topics could be ascribed to a single text. This because texts (like news articles) tend to be more articulated (addressing even multiple issues/contents) while ads tend to focus on a single key issue or content.

Three pairs of analysts carried out the analysis of the texts, first working individually and then comparing the coded material. The cases for which discrepancies were found were discussed comparing the different "readings" until a shared code was identified. This collegial mode of analysis is a crucial step in content analysis in order to systematically control for the risks of subjective interpretation (Berelson, 1952; Holsti, 1969).

\section{Results (study 1)}

\subsection{Main topics/themes}

Twenty-two different topics/themes were identified (see Table 1). In particular, the bike was mentioned, described or visually represented in units of analysis (either news articles or commercial advertisements) that dealt with themes of environmental relevance such as "ecology," "environment," "pollution," "sustainable mobility," "traffic" and "city planning." Similar associations were found between the bike and themes of social and/or personal relevance linked to safety and security ("physical integrity," "accidents," "thefts"), and "sociality" and "economic welfare". Moreover, associations were found between the bike and themes linked to hedonism ("fun", "leisure", "adventure", "dynamism" and "strength"), habits ("comfort" and "lifestyle"), emotions ("love" and "sensuality") and well-being ("physical well-being", "beauty").

A different distribution of topics throughout the units of analysis was also noticed, which deserves to be mentioned. In particular, while dynamism, physical well-being, fun and sociality recurred in all of the units of analysis, others were more represented in some units than others. In this sense, commercial advertisements tended to make references to the bike by using the economic and hedonistic benefits derived from riding it as appealing messages. No references to issues such as sustainability, safety/security, traffic, city planning and lifestyles were found in such units, whereas these aspects received greater attention in the news articles (both traditional and online press).

Table 1

Main topics addressed by the units of analysis (TV commercials, press ads, traditional and online news articles) in which the bicycle was mentioned and/or visually represented.

\begin{tabular}{|c|c|c|c|c|c|c|c|}
\hline \multirow[t]{3}{*}{ Topics } & \multicolumn{3}{|l|}{ TV commercials } & \multirow{3}{*}{$\begin{array}{l}\text { Ads in the press }(N=38)^{\mathrm{a}} \\
f\end{array}$} & \multirow{3}{*}{$\begin{array}{l}\text { Traditional press }(N=30)^{\mathrm{b}} \\
f\end{array}$} & \multirow{2}{*}{\multicolumn{2}{|c|}{$\begin{array}{l}\text { On line press } \\
(N=405)^{\mathrm{b}}\end{array}$}} \\
\hline & \multirow{2}{*}{$\begin{array}{l}\text { Single spot }(N=12) \\
f\end{array}$} & \multicolumn{2}{|c|}{$\begin{array}{l}\text { Repeated spot } \\
(N=610)\end{array}$} & & & & \\
\hline & & $f$ & $(\%)$ & & & $f$ & $(\%)$ \\
\hline Dynamism & 4 & 134 & $(22.0)$ & 8 & 2 & 173 & $(42.7)$ \\
\hline Environment & - & - & - & - & 11 & 168 & $(41.5)$ \\
\hline Safety, physical integrity & - & - & - & - & 7 & 156 & (38.5) \\
\hline Lifestyles & - & - & - & - & 6 & 154 & $(38)$ \\
\hline City planning & - & - & - & - & 13 & 153 & $(37.8)$ \\
\hline Sustainable mobility & - & - & - & - & 10 & 135 & (33.3) \\
\hline Pollution & - & - & - & - & 10 & 126 & (31.1) \\
\hline Leisure & - & - & - & - & 5 & 123 & (30.4) \\
\hline Ecology & - & - & - & - & 12 & 122 & (30.1) \\
\hline Traffic & - & - & - & - & 12 & 122 & (30.1) \\
\hline Physical wellbeing & 2 & 29 & $(4.8)$ & 9 & 1 & 116 & $(28.6)$ \\
\hline Comfort & - & - & - & - & 6 & 115 & $(28.4)$ \\
\hline Accidents & - & - & - & - & 1 & 104 & (25.7) \\
\hline Economic wellbeing & 2 & 238 & $(39.0)$ & - & 3 & 104 & $(25.7)$ \\
\hline Fun & 1 & 28 & $(4.6)$ & 2 & 1 & 104 & (25.7) \\
\hline Sociality & 1 & 96 & (15.7) & 4 & 1 & 92 & (22.7) \\
\hline Adventure & - & - & - & 6 & - & 85 & (21) \\
\hline Beauty & - & - & - & 3 & 1 & 84 & $(20.7)$ \\
\hline Security, theft & - & - & - & - & 3 & 46 & (11.4) \\
\hline Strength & - & - & - & 1 & - & 44 & (10.9) \\
\hline Love & 2 & 85 & (13.9) & 1 & - & 33 & $(8.1)$ \\
\hline Sensuality & - & - & - & - & - & 5 & $(1.2)$ \\
\hline
\end{tabular}

Note: $f=$ frequencies; percentages were reported for samples with $N>100$ only.

a Four ads could not be coded into any of the categories and were included in the "other" category, not reported in the table.

b For online and traditional news articles, multiple topics could be ascribed to a single text, for this reason the total number of cases exceeds the total number of units of analysis. For example, 'Dynamism', referring to pro-activity/movement/energy) was detected in 173 online articles, corresponding to $42.7 \%$ of all the 405 articles considered, while 'Strength', referring to mental and physical power/domination, was detected in 44 online articles, corresponding to $10.9 \%$ of all the articles considered. 
Table 2

Characteristics of the "cyclist" as they emerge from the units of analysis (TV commercials, press ads, traditional and online news articles).

\begin{tabular}{|c|c|c|c|c|c|c|c|}
\hline & \multicolumn{3}{|c|}{ TV commercials } & \multirow{3}{*}{$\begin{array}{l}\text { Ads in the } \\
\text { press }(N=38) \\
f\end{array}$} & \multirow{3}{*}{$\begin{array}{l}\text { Traditional } \\
\text { press }(N=30) \\
f\end{array}$} & \multirow{2}{*}{\multicolumn{2}{|c|}{$\begin{array}{l}\text { On line press } \\
(N=405)\end{array}$}} \\
\hline & \multirow{2}{*}{$\begin{array}{l}\text { Single spot } \\
(N=12) \\
f\end{array}$} & \multicolumn{2}{|c|}{$\begin{array}{l}\text { Repeated spot } \\
(N=610) \\
\end{array}$} & & & & \\
\hline & & $f$ & $\%$ & & & $f$ & $\%$ \\
\hline Sex & & & & & & & \\
\hline Male & 4 & 238 & 39 & 14 & 2 & 117 & 55.5 \\
\hline Female & 2 & 29 & 4.8 & 6 & 1 & 20 & 9.5 \\
\hline Both & 5 & 336 & 55.1 & 14 & - & 53 & 25.1 \\
\hline Age & & & & & & & \\
\hline Old & 1 & 24 & 3.9 & 3 & - & 27 & 12.8 \\
\hline Adult & 6 & 450 & 73.9 & 25 & - & 65 & 30.8 \\
\hline Joung & 3 & 101 & 16.6 & 4 & - & 25 & 11.8 \\
\hline Child & 1 & 28 & 4.6 & 1 & - & 5 & 2.4 \\
\hline Interaction & & & & & & & \\
\hline Absent & 1 & 33 & 5.4 & 12 & - & 71 & 17.5 \\
\hline Affective & 4 & 391 & 64.1 & 12 & 1 & 43 & 10.6 \\
\hline Professional & - & - & - & - & 1 & 17 & 4.2 \\
\hline Activities & & & & & & & \\
\hline Cultural & - & - & - & - & 3 & 74 & 18.3 \\
\hline Leisure & 2 & 81 & 13.3 & 14 & - & 62 & 15.3 \\
\hline Accidents & - & - & - & - & - & 55 & 13.6 \\
\hline Helmet & & & & & & & \\
\hline Absent & 9 & 561 & 92 & - & 1 & 198 & 48.9 \\
\hline Present & 2 & 42 & 6.9 & - & 1 & 13 & 3.2 \\
\hline Clothing & & & & & & & \\
\hline Casual & 8 & 522 & 85.6 & - & 1 & 11 & 2.7 \\
\hline Protective & - & - & - & - & - & 18 & 4.4 \\
\hline
\end{tabular}

\subsection{The representation of the "cyclist"}

Half (52\%) of the online articles referred explicitly to the figure of the "cyclist." This figure was mainly that of an adult (30.8\%), man (55.5\%) who interacted with other people (14.8\%) in situations of affective (10.6\%) or professional (4.2\%) types. "The cyclist" used the bike for cultural (18.3\%) or leisure (15.3\%) activities, or was involved in road accidents (13.6\%). A scarcity of references to the use of protective gear was noticed. For example, references to the use of the helmet was present in only $3.2 \%$ of the cases, while the use of protective clothing was mentioned in $4.4 \%$ of the cases. Similar trends were also found for traditional press (see Table 2), while in TV and press ads, cyclists are primarily adults (both male and female), using the bike for leisure motives in affective situations. References to the helmet and/or protective clothing are virtually absent in TV and press ads.

\subsection{Grouping topics, values, social context and the characteristics of the text}

A cluster analysis ${ }^{6}$ was performed on the articles from the online press (the other units of analysis had to be dropped because samples were too small) in order to assess whether, for example, specific combinations of certain topics, themes, values, etc. recurred within the different types of news articles. A three-cluster solution was eventually chosen. Table 3 reports the detailed composition of the three clusters in terms of the characteristic variables. Table 4 specifies the composition of the three clusters in terms of the values associated with them.

Cluster 1, named "risk and danger," identifies a large group of articles (182, 44.94\%) that is mainly composed of short/ flash news that report road accidents and their consequences, as well as episodes of physical assaults, robberies and thefts. The main theme of these articles concerns the bicycles in their everyday struggle with a variety of urban antagonists (cardrivers, pedestrians, criminals, robbers). Coherently, the discourses seem to appeal to values related to security and universalism (i.e. the belief that an Authority is required to warrant the Safety of one's own loved ones and to ensure Social Justice).

Cluster 2, named "sustainable mobility," gathers a group of extensive and authoritative articles $(132,32.59 \%)$ that deals with the scientific, political, managerial and economical aspects of sustainable mobility. They address issues such as ecology, environment, and traffic, suggesting practical solutions and/or prompting the readers to increase their personal commitment in different practices like changing their lifestyle and transport habits. The bike is depicted here as an alternative to more unsustainable transport solutions for everyday necessities. The discourses seem to appeal to both biospheric and wealth values, which is in line with the general tenets of sustainable development that aim to integrate ecocentric and anthropocentric perspectives.

\footnotetext{
${ }^{6}$ All significant variables (topics, values, social context and characteristics of the text) were used for the clustering procedure. The analysis was performed using the SPAD (Système portable pour l'analyse des données) software, which applies a mixed algorithm, initially non-hierarchical and then iterative.
} 
Table 3

Clusters characterisation.

\begin{tabular}{|c|c|c|c|c|c|c|c|}
\hline Clusters & Items $^{\mathrm{a}}$ & Categories & $\begin{array}{l}\% \text { Of category } \\
\text { in group }\end{array}$ & $\begin{array}{l}\% \text { Of } \\
\text { category in } \\
\text { set }\end{array}$ & $\begin{array}{l}\% \text { Of group in } \\
\text { category }\end{array}$ & $\begin{array}{l}\text { Test } \\
\text { value }\end{array}$ & Weight \\
\hline \multirow{10}{*}{$\begin{array}{l}\text { Cluster } 1 \text { "Risk and danger" } \\
\quad(n=182 ; 44.94 \%)\end{array}$} & Placement & Crime news & 71.43 & 35.06 & 91.55 & 14.48 & 142 \\
\hline & $\begin{array}{l}\text { Safety (physical } \\
\text { integrity) }\end{array}$ & Present & 64.84 & 38.52 & 75.64 & 9.90 & 156 \\
\hline & Road accidents & Present & 48.90 & 25.68 & 85.58 & 9.83 & 104 \\
\hline & Expert advice & Absent & 67.03 & 41.73 & 72.19 & 9.37 & 169 \\
\hline & Topic description & $\begin{array}{l}\text { Problematized } \\
\text { without solution }\end{array}$ & 39.01 & 20.25 & 86.59 & 8.63 & 82 \\
\hline & Security (theft) & Present & 23.08 & 11.36 & 91.30 & 6.87 & 46 \\
\hline & Level of depth & Satisfactory & 57.69 & 40.49 & 64.02 & 6.30 & 164 \\
\hline & Type of news & News flash & 29.12 & 16.79 & 77.94 & 5.94 & 68 \\
\hline & Level of depth & Unsatisfactory & 6.59 & 3.46 & 85.71 & 2.91 & 14 \\
\hline & Topic description & $\begin{array}{l}\text { Problematized with } \\
\text { solution }\end{array}$ & 8.79 & 5.19 & 76.19 & 2.75 & 21 \\
\hline \multirow[t]{18}{*}{$\begin{array}{l}\text { Cluster } 2 \text { "Sustainable mobility" } \\
\qquad(n=132 ; 32.59 \%)\end{array}$} & $\begin{array}{l}\text { Sustainable } \\
\text { mobility }\end{array}$ & Present & 88.64 & 33.33 & 86.67 & 16.87 & 135 \\
\hline & Ecology & Present & 81.82 & 30.12 & 88.52 & 15.98 & 122 \\
\hline & Environment & Present & 93.94 & 41.48 & 73.81 & 15.61 & 168 \\
\hline & Pollution & Present & 81.82 & 31.11 & 85.71 & 15.49 & 126 \\
\hline & Traffic & Present & 71.97 & 30.12 & 77.87 & 12.63 & 122 \\
\hline & City planning & Present & 78.03 & 37.78 & 67.32 & 11.63 & 153 \\
\hline & Placement & $\begin{array}{l}\text { Politics, economics, } \\
\text { finance }\end{array}$ & 77.27 & 38.27 & 65.81 & 11.23 & 155 \\
\hline & Expert advice & Direct & 73.48 & 40.25 & 59.51 & 9.44 & 163 \\
\hline & Attitude change & Orientation & 62.12 & 33.58 & 60.29 & 8.27 & 136 \\
\hline & Usefulness & Present & 98.48 & 85.43 & 37.57 & 5.73 & 346 \\
\hline & Lifestyles & Present & 56.82 & 38.02 & 48.70 & 5.28 & 154 \\
\hline & Framework & Cultural events & 9.85 & 4.20 & 76.47 & 3.55 & 17 \\
\hline & $\begin{array}{l}\text { Economic } \\
\text { wellbeing }\end{array}$ & Present & 37.12 & 25.68 & 47.12 & 3.49 & 104 \\
\hline & Comfort & Present & 39.39 & 28.40 & 45.22 & 3.26 & 115 \\
\hline & Topic description & $\begin{array}{l}\text { Problematized with } \\
\text { solution }\end{array}$ & 36.36 & 25.93 & 45.71 & 3.17 & 105 \\
\hline & Attitude change & Conversion & 12.12 & 6.17 & 64.00 & 3.13 & 25 \\
\hline & $\begin{array}{l}\text { Attitude } \\
\text { dimension }\end{array}$ & Conative & 18.18 & 10.86 & 54.55 & 3.03 & 44 \\
\hline & Level of depth & Excellent & 26.52 & 18.27 & 47.30 & 2.80 & 74 \\
\hline \multirow{18}{*}{$\begin{array}{l}\text { Cluster } 3 \text { "Wellness and leisure" } \\
\qquad(n=91 ; 22.47 \%)\end{array}$} & Adventure & Present & 62.64 & 20.99 & 67.06 & 10.21 & 85 \\
\hline & Dynamism & Present & 85.71 & 42.72 & 45.09 & 9.52 & 173 \\
\hline & Fun & Present & 64.84 & 25.68 & 56.73 & 9.11 & 104 \\
\hline & Sociality & Present & 59.34 & 22.72 & 58.70 & 8.78 & 92 \\
\hline & Leisure & Present & 65.93 & 30.37 & 48.78 & 7.98 & 123 \\
\hline & Topic description & Unproblematized & 84.62 & 48.64 & 39.09 & 7.94 & 197 \\
\hline & Framework & Freetime, leisure & 69.23 & 35.06 & 44.37 & 7.50 & 142 \\
\hline & Strenght, force & Present & 34.07 & 10.86 & 70.45 & 7.14 & 44 \\
\hline & Placement & Sport activities & 19.78 & 4.44 & 100.00 & 7.13 & 18 \\
\hline & Beauty & Present & 49.45 & 20.74 & 53.57 & 7.06 & 84 \\
\hline & $\begin{array}{l}\text { Physical } \\
\text { wellbeing }\end{array}$ & Present & 52.75 & 28.64 & 41.38 & 5.46 & 116 \\
\hline & Placement & Gossip & 14.29 & 4.69 & 68.42 & 4.18 & 19 \\
\hline & Level of depth & Excellent & 32.97 & 18.27 & 40.54 & 3.79 & 74 \\
\hline & Type of news & Report & 27.47 & 14.57 & 42.37 & 3.60 & 59 \\
\hline & Placement & Culture & 13.19 & 5.19 & 57.14 & 3.34 & 21 \\
\hline & Attitude change & Orientation & 47.25 & 33.58 & 31.62 & 2.97 & 136 \\
\hline & Love & Present & 16.48 & 8.15 & 45.45 & 2.90 & 33 \\
\hline & Lifestyles & Present & 49.45 & 38.02 & 29.22 & 2.41 & 154 \\
\hline
\end{tabular}

Note: Table 3 shows the percentage of cases with the considered mode in each cluster (\% of category in group); the percentage of cases with the considered mode in the total sample (\% of category in set); the percentage of cases with the considered mode that falls within the cluster on the sample total (\% of group in category). All test values are significant at the 0.01 level.

a 'Placement' and 'Type of news' are items of the first thematic area: Structural and formal aspects of the text; topics like "Dynamism, Environment, Lifestyles, Sustainable mobility, Pollution, Leisure, Ecology, Traffic, Comfort, Fun, Beauty, Security-theft, Love, Safety (Physical integrity), Road accidents, City planning, Usefulness, Economic wellbeing, Adventure, Sociality, Strength-force, Physical wellbeing" are items of the second thematic area Topic and context description as well as "Framework". "Expert advice", "Topic description", "Level of depth", "Attitude change", are items of the third thematic area Communication analysis. "Attitude dimension" is an item of the fourth thematic area Attitude and values. 
Table 4

Clusters characterisation in terms of values.

\begin{tabular}{|c|c|c|c|c|c|c|}
\hline Clusters & Values & Cluster mean & Overall mean & Cluster std. deviation & Overall std. deviation & Test value \\
\hline \multirow[t]{4}{*}{ Cluster 1 "Risk and danger” } & Social justice & 1.511 & 0.952 & 1.245 & 1.187 & 8.56 \\
\hline & Authority & 0.744 & 0.476 & 0.944 & 0.837 & 5.83 \\
\hline & Family security & 0.644 & 0.425 & 0.873 & 0.777 & 5.12 \\
\hline & A world at peace & 0.272 & 0.195 & 0.556 & 0.488 & 2.88 \\
\hline \multirow[t]{4}{*}{ Cluster 2 "Sustainable mobility" } & Preventing pollution & 1.937 & 0.787 & 1.189 & 1.178 & 13.34 \\
\hline & Respecting the earth & 1.906 & 0.835 & 1.193 & 1.187 & 12.32 \\
\hline & Unity with nature & 1.268 & 0.585 & 1.097 & 0.947 & 9.86 \\
\hline & Wealth & 0.906 & 0.719 & 1.090 & 1.053 & 2.42 \\
\hline \multirow[t]{3}{*}{ Cluster 3 "Wellness and leisure" } & Curiosity & 1.466 & 0.534 & 0.976 & 0.842 & 11.75 \\
\hline & An exciting life & 1.500 & 0.597 & 1.022 & 0.887 & 10.81 \\
\hline & A varied life & 1.750 & 0.808 & 1.069 & 0.993 & 10.09 \\
\hline
\end{tabular}

Note: Table 4 shows the mean, standard deviation and test value. All test values are significant at the 0.01 level.

Finally, cluster 3, named "wellness and leisure," gathers a group of articles $(91,22.47 \%)$ dealing with the themes of physical wellbeing, adventure (also in terms of competition) and fun. The bicycle is depicted here in light of its "therapeutic" properties and/or of the hedonistic opportunities that it might offer. It appears as a means of transportation to be used during one's spare time and for health and/or leisure purposes in general. In particular, these articles mention the bike based on the way it can contribute to improving health, mood, socialisation, exploration and knowledge. It is therefore not surprising that the values to which these articles seem to appeal are related to openness to change.

\section{Conclusion (study 1)}

Three sets of meanings were found to be associated with the bike in the on line press in Italy: (1) the risks and dangers linked to road accidents and criminal assaults, (2) the benefits to the environment and the urban mobility that could be derived from systematic use of the bike and (3) the positive effects that riding a bike could have at the social (interpersonal relationships) and personal level (physical and psychological well-being). In other words, the mass media discourses on the bike were quite articulated, as they included both potential benefits and drawbacks. Future studies could assess whether benefits are reported more often than drawbacks (or vice versa) and whether media tend to differ with regard to the topics and meanings that they choose to communicate in relation to the bicycle. For example, cues were found that a difference might exist between the representation of the bike by news articles (either traditional or online press) and the one presented by the commercial advertisements aired on TV or published in paper magazines. In particular, it seemed that road accidents and physical assaults tended to be overrepresented in the news articles. This might be due to the typical tendency of newspapers to over-represent negative episodes in general (and conversely there is the tendency of commercial advertisements to rely on the positive sides of the topics that they address). However, more studies are needed in order to understand the prevailing image of the bike and whether this might have any correlation with the representation of the bike held by the public. An attempt to answer the latter question was done in study 2.

\section{Method (study 2)}

\subsection{Participants}

Ninety-four residents of the city of Rome were interviewed for study 2 . These were equally distributed in terms of sex, and approximately balanced by age (32 were in the age range of $18-30$ years, 34 were of 30-50 years and 32 were over 50 years old). Most of them (45) had a high school degree, 30 had a university degree and the remaining 25 had either a middle high school or a primary school degree. The participants' professional status was also recorded and resulted in quite a heterogeneous mix of professions, including employees, teachers, social workers, retirees, housewives, and others. Most of the participants did not use a bike on a regular basis, but 10 of them asserted to commuting by bike everyday either to school or to work and to use it very often in general. Two participants were not able to ride a bike. Although the distribution of bikers and non-bikers appears as uneven, it is worth noticing that the percentage of habitual cyclists within our sample is comparable to that existing in the overall population of Rome.

\subsection{Procedure and interview schedule}

Interviews lasted for 5-10 min each and were semi-structured, including seven open-ended questions in addition to those concerning social demographical factors. Participants were first asked whether they used or did not use a bike on a regular basis for their daily travel necessities (including going to work or to school) in Rome. Then, they were interviewed with regard to their behavioural and normative beliefs concerning the use of bikes in the city (the interview schedule is reported in Appendix A). 


\subsection{Data analysis}

Participants' responses were analysed using a combination of two different approaches. As a first step, following Fishbein and Ajzen (e.g. 2010), participants' overall answers to each question were grouped and kept separate from their answers to the other questions. As a second step, a grounded theory approach (Glaser \& Strauss, 1967; Strauss \& Corbin, 1990) was adopted in order to analyse the overall answers to each questions, following Strauss and Corbin's (1990) guidelines. More specifically, all the different topics emerging from the overall answers to a particular question were initially identified and coded by assigning them specific conceptual labels (primary codes). This phase of analysis is usually indicated by the literature on grounded theory as "open" coding, and it is usually followed by an "axial" coding phase in which overarching categories are detected in order to gather groups of primary codes. This progressively inclusive process can be continued until the researcher reaches the intended level of reduction and understanding of the data collected, and can also take the form of a "selective" coding process aimed at identifying relationships (for eg. association, causality, contradiction, similarity, inclusion, property, etc) among the categories detected. The data collected were subjected to the first two phases mentioned above. Tables 5 and 6 provide a synthetic description of the main results together with examples of participants' statements for each category of response identified.

Table 5

Positive beliefs associated to the use of bike in the city with corresponding extracts from participants (P) responses provided as examples.

(1) Practical convenience (saving money, saving time, avoiding specific kinds of risk, parking easily, moving easily in the city streets)

P4: "Considering the numerous consequences and costs deriving from the thoughtless use of automobiles, we would all save much money [...]"

P2: "It makes me save time, I do not pay for the car fuel and insurance"

P15: "I would save lots of money from the fuel and the gym"

P61: "I would avoid receiving police fines so often as I am used to"

P1: "I would not lose time waiting for the buses"

P9: "I would arrive on time at my appointments, given that the time reliability of the public means [of transportation] is null [...]"

P23: "I would not have parking problems anymore"

P79: "It would be an alternative to be forced to look for a parking each time I go somewhere"

P17: "I could arrive earlier [at destination] getting out of the traffic by riding on the sidewalks"

P67: "I would avoid going on foot or asking my colleagues for a lift"

P91: "I would not be forced to ask my children to take me to someplace, given that I do not drive any longer".

P57: "I would arrive earlier because it would be an alternative to go on foot [...]"
(2) Physical and mental wellness (doing physical exercise; the bike brings good-mood, relaxation, distraction, independence, inspiration, and let riders "discover" their own city)

P8: "I would do some sport activity"

P36: "I would do sport, I would be in a better health condition"

P47: "It would help me with my diet and I would do some movement"

P51: "It would distract me from the anxiety of my job"

P63: "I would avoid feeling stressed in the traffic" P78: "[...] I would move with more calm and this would soothes me a lot"

P38: "It would made many people feel relaxed and it would alter the quality of life of everyone[...]"

P10: "I would enjoy the city more"

P31: "I feel free, I can see and observe the things that I could not see [if I was] closed in a car, and it makes me feel good psychophysically"

P37: "[... I I could better observe the places I go to, the city would be much more beautiful [...]"

P39: “[...] there would be much more contact with the things around me [...]"

P42: "It gives me good mood and makes me noticing different particulars because it allows to choose alternative ways"

P80: "I could enjoy Rome landscape much more, and, as l've just moved here, I would learn more things and know more places".

P43: "When I pedal I feel happy, free from timetables, bus strikes, waits at the bus stop, or traffic queues like when I go by car, and I have no parking problems"

P3: "I could be autonomous even at night" P84: "I would be more in contact with nature and considered that I paint, I would be inspired in treating more interesting subjects.
(3) Sustainability and (4) socialisation (reducing pollution and congestion, meeting with those who share the same interest, education)

P5: "It would reduce environmental and acoustic pollution, it would reduce car traffic $[\ldots] "$

P37: "The air would be more breathable [...]"

P44: "[...] it's good for the city in general (because I do not emit $\mathrm{CO} 2$ )"

P53: "There would be more clean air"

P68: "There would be less pollution"

P85: "In this way there would be less smog [...]"

P37: "[...]there would be more socialization"

P40: "[...] I would socialize more"

P12: "It's an educational means, you learn to work hard and to understand other people's strain" 
Table 6

Negative beliefs associated to the use of bike in the city with corresponding extracts from participants (P) responses provided as examples.

(1) Structural organisation of the city (causing safety and security problems)

I would use the bike for my travel necessities in this city more often if ...

P6: "if there were more appropriate facilities (cycling lanes) bike lanes"

P37: "if the city were safer (more cycling lanes) [...]"

P38: "Now I use it for short trips, but I would use it more often if there were more lanes for bikes"

P74: "if I lived downtown where there are more cycling lanes [...]"

P14: "There's too much traffic and the spaces dedicated to bikes are reduced"

P74: "The city streets are not organized to ride bikes"

P89: "I would not know where to go, because the cycling lanes... I think they are only downtown and it would be dangerous to pedal among the cars"

P90: "Rome, besides the traffic problems, has also the problem of potholes and this would increase the risk of falling down"

Using the bicycle more often for my travel necessities would be a problem for me, because. .

P39: "There's too much traffic, there is no safety, I would feel too vulnerable"

P34: "There's no way to use a bike without danger because of the traffic"

P75: "There are too many cars, and I would risk my life each time"

P87: “[...] although interesting and amusing, still it would be dangerous"

P9: "I [would] breath too much smog"

P49: “As I work in a hospital I often do the night shift, and there would be a problem because would have to ride the bike in the dark, and I would fear for my safety"

P70: "As I work during the night, it would be dangerous in the streets I have to go through, also because I would fear to be assaulted"

P3: "There's a risk that someone could steal it [the bike] [...]"

P40: "I wouldn't know where to park it to avoid the risk of theft [... ."

P68: "They could steal my bike [if I park it] outside the school"
(2) Territorial characteristics of the city (size, hilliness, climate)

I would use the bike more often if ...

P14: "[...] if the distances between the place where I live and the place where I work would be short" P39: “[...] if the city weren't so extensive [...]"

P64: "if I would not have to take the loop to go to work"

P82: "if the distances in the city were shorter and [the city] were more on a human scale"

P15: “[...] if there weren't so many slopes [...]"

P20: "[...] if Rome were all flat"

P33: “[...] if Rome were not on 7 hills [this person refers to the fact that according to the tradition Rome, in its origins, was built on 7 hills; hence, the metaphor is here used to say that Rome is not a flat city]

Using the bicycle more often for my travel necessities would be a problem for me, because. .

P13: “Destinations are far and I am not trained for"

P36: "Because of the city size"

P42: "I have to move everyday from one area of city to the other, and I cannot take the bike with me in the subway"

P44: "Some distances are too extensive [...]"

P37: "If it rains, if it's cold, because of weather conditions"

P48: "The problem is in winter, even when it doesn't rain, it's cold, then I avoid using the bike"

P72: "In summer is very hot [...]"

P73: "When it rains I would get wet and when there's the sun I would arrive wet at destination"
(3) Structural characteristics of the bike (carrying capacity)

I would use the bike more often if ...

P55: "if before going to work I didn't have to take my children to school" P32: “[...] if I didn't have to carry my work tools with me"
Using the bicycle more often for my travel necessities would be a problem for me, because...

P86: “I wouldn't know where to put my daughter and the shopping bags" P93: "it would take double as time to go shopping in order to reach all the various supermarkets"

P87: "when I have to do shopping, I

wouldn't know where to put the shopping bags [...]"

P29: "to go shopping, too many bags, to go downtown too many cars"

P30: "I live far away and I often have to carry materials for my job"

P54: "because of my job I need to load and unload products from my car, with the bike I wouldn't know how to do"
(4) Congruence with one's own age, professional status, clothing style and fashion

I would use the bike more often if . .

P50: "If I was used to wear casual clothes and shoes"

P68: "If everybody used the bikes, because it would be like a fashion"
(5) Personal physical and psychological limits

I would use the bike more often if. .

P41: "If it weren't for laziness"

P22: "If I were more physically trained"

P93: "If I had the strength to pedal [...]

P10: "If I felt the necessity"

P40: "[...] If the price of the fuel would rise again"

P23: "If it was an electric bike"

P37: "if it were less tiring"

P63: "if I were less tired when I come out of the office to jump on a bike and pedal till home".

P47: "If I weren't a slave of the use of car"

P81: "If I had more time to be able to ride during the day" P93: "If I could dedicate more time to myself and I had to do less things at home" 
Using the bicycle more often for my travel necessities would be a problem for me, because...

P66: "I need to dress up adequately when I go to work and it would be complicated to pedal with the heels [wearing high heeled shoes]"

P68: "I would have to ride for a long way and, as I usually wear the suit, I would risk to torn it pedaling for so long"

P80: "I always wear jacket and tie and it would not be practical to ride a bike"

P59: "The status I occupy at my workplace does not allow me to let people at my workplace see that I go to work by bike".

P60: "I am over 60 and I would feel ridiculous if people at my workplace saw me arriving on a bike"
P30: “[...] If I didn't smoke so much [...]"

Using the bicycle more often for my travel necessities would be a problem for me, because...

P18: "I am very lazy"

P61: "In the morning I would be forced to pedal for severa kms right after having waken up"

P10: "It would be tiring physically and mentally"

P65: "I live just in front of my university, I would lose time riding a bike to go there"

P76: "I suffer from low blood pressure and in summer I could faint"

P43: "I suffer from asthma and sometimes I get trouble with the smog [...]"

P47: "It would be tiring for me, because I am overweight" P35: "[...] I have a problem to the ligaments"

P94: "After few thrusts on the pedal I would feel pain at my legs"

\section{Results (study 2)}

\subsection{Positive and negative behavioural and normative beliefs}

All participants were able to identify and report at least one positive aspect that supported the use of bikes in the city, while four participants expressed that they did not see any negative aspects linked to bike use. These four people used to riding a bike in the city regularly. On the overall, most participants were able to speak both in favour of and against the use of bikes in the city and a crucial point to notice is that in many cases such beliefs appeared to be anchored to specific (positive and/or negative) emotions. All these aspects will be described more in detail here following.

\subsubsection{Positive behavioural beliefs}

Four main overarching categories of positive beliefs were identified. In particular, using a bike for daily transportation necessities emerged as a good way to enhance: (1) physical and psychological wellness, (2) practical convenience, (3) sustainability and (4) socialisation.

\subsubsection{Physical and psychological wellness}

Around $46 \%$ of the overall positive beliefs recorded concerns physical and mental wellness. A number of participants $(n=39)$ stated that riding a bicycle is good for enhancing physical wellness as it is physical exercise. Meanwhile, it could also help mental wellness in various ways: it is relaxing (14) and can increase overall quality of life (1); it can give the rider a sense of freedom (4) and it is able to bring feelings of happiness and good mood in general (3). Moreover, it is considered a way to stay more in contact with nature and to get inspired (1). Finally, it can be a way to enjoy/discover the "beauties" of the city (11).

\subsubsection{Practical convenience}

Many respondents $(n=59)$ consistently associated several practical advantages to the use of bike in the city. These responses correspond to about $38 \%$ of the overall positive beliefs identified. Economic advantages were mentioned the most often (16), and included saving money from car fuel and car insurance (14), and avoiding paying police fines (1) or gym fees (1). It was considered more practical than using public transportation (7) or driving a car (6). In the first case, because one does not have to waste time waiting at bus stops, in the other, because the bike can be parked more easily and waiting in the traffic can be avoided. Moreover, those who cannot drive or do not own a private car would not have to ask friends, colleagues or relatives for lifts (3) or would not have to go by foot (1).

\subsubsection{Sustainability and socialisation}

Riding a bike in the city can also help the environment $(n=21 ; 14 \%$ of the overall positive beliefs identified) by reducing air and acoustic pollution (15) and solving traffic problems (4). Three participants suggested that riding a bike could also help to socialise with others and that it may have important educational implications ( $2 \%$ of the overall positive beliefs identified).

\subsubsection{Negative behavioural beliefs}

Five overarching categories of negative beliefs were also identified. These were respectively named: (1) Structural organisation of the city (which causes safety and security problems), (2) Structural characteristics of the city territory (which render riding a bike uncomfortable) and (3) Structural characteristics of the bike (which limit the capacity of carrying things and people). The remaining categories gathered the beliefs that were linked to the way in which riding a bike could be congruent with, on the one hand, one's own (4) identity and social status, professional occupation, age, clothing style and fashion and, on the other hand, one's own general attitude towards doing physical activity, together with the (5) perceived 
personal physical capacity of doing it. The five categories were all manifestly linked to fears of various types, the most prominent of which was the possibility of road accidents.

\subsubsection{Structural organisation of the city}

Almost all of our participants (including those who declared to use the bike regularly) were convinced that the city does not support the use of bikes. The main obstacle that was perceived concerned the way in which the city is organised and managed ( $51 \%$ of all negative beliefs). Too much traffic combined with a lack of facilities for bikes make participants feel that riding in Rome is dangerous and that those who do it put their life at serious risk. Indeed, numerous respondents declared that they would use a bike more often if the city could be adequately endowed with all of these facilities (37), and more generally if the city streets could be in better condition (5) so as to avoid the risk of falling and getting hurt. Aside from the lack of facilities, deterrents to bike use also included the fact that, in general, the city is seen to be too chaotic (33) and polluted (19), thus not only unsafe but also unhealthy to support the use of bikes. Furthermore, some also mentioned the risk of being assaulted during the trip (2) or being a victim of bike theft (3).

\subsubsection{Territorial characteristics of the city}

The characteristics of the city territory can be another problem for cyclists in Rome (23\% of all negative beliefs). Participants reported that some of their daily principal destinations (such as schools or workplaces) are too far to be reached by bike (24), and that in general the city is too wide (4). Moreover, the city territory is not always flat (6), which is a condition that some consider essential to riding a bike. Another prerequisite for bike riding is good weather (7).

\subsubsection{Structural characteristics of the bike}

The bike was also seen as having some intrinsic structural limits that can hamper its daily use, especially when compared to other means of transportation such as cars (10\% of all negative beliefs). In particular, it cannot carry as many people and as much weight as a car (15), and thus it is not suitable for a person who has a job that requires carrying heavy materials or goods (5). Moreover, some people might not be able to ride it at all (5).

\subsubsection{Congruence with one's own age, professional status, clothing style and fashion}

Other limits identified concerned the congruence of the use of bikes with aspects related to one's own identity, image and social/professional role ( $5 \%$ of all negative beliefs). In particular, there were cases in which the use of bikes can be incongruent with the real or perceived requirements of one's job in terms of appropriate behaviours and decency of the image presented to customs, patients and colleagues. In this sense, six participants expressed that they felt uncomfortable with the idea of riding a bike, for example to go to work, because it would entail having to change clothes or even take a shower when arriving at the workplace. One participant reported that riding the bike to go to work was not proper for him/her given his/ her professional status (in a managerial role). Another one suggested that riding a bike is not socially acceptable for people at his/her advanced age. Finally, one asserted that he/she would ride the bike more often if it was considered to be fashionable.

\subsubsection{Personal, physical and psychological limits}

Finally, participants reported some personal limits clearly linked to their general attitude towards riding a bike and doing physical activity ( $11 \%$ of negative beliefs). These were namely being lazy (3), being physically unprepared (2), being uninterested in using such a means of transportation (4), perceiving it as too tiring (3) being very used to driving cars (1), having little time to dedicate to riding a bike (2) and having real or perceived health problems that hinder riding a bike (6).

\subsection{People and categories that participants thought would approve and disapprove if they used the bike for their daily transport} necessities in Rome

Overall, participants mentioned a wide range of possible interlocutors that belonged to practically all spheres of their personal and social life: family, friendship, peers, workplace, neighbourhood, citizenship, society. Nevertheless, it was difficult to clearly delineate a consistent position for each category, as in many cases a person or a category was mentioned both as one that would approve and disapprove of bike riding, according to different motivations.

\subsubsection{People and categories that would approve of participants using a bike in the city}

Friends, colleagues and acquaintances who already use a bike or share the same values as the respondent were cited more often (20) as people who would approve of the use of bikes in the city. Reasons ranged from the benefits this would bring to the environment to the opportunity for the respondent to join them (who already use a bike). Another reason cited was that it is generally good for one's health. This was also recurrently mentioned as a reason that partners (boyfriends, girlfriends, husbands, wives) and/or family members (sons, daughters, parents) would approve such behaviour (22). The categories mentioned more often under approval of bike use were cyclists (9) and movements actively engaged in promoting the use of bikes in the city (17), like Critical Mass or the so called "popular cycle garages." Fourteen participants suggested that

\footnotetext{
${ }^{7}$ Garages in which people can repair their bike for free or buy recycled ones at convenient prices.
} 
approval would come from categories that have economic interests linked to bikes (bike producers, sellers, rentals, repairs), while another six mentioned specific political groups (members of the green party, social movement of the so-called left wing). A variety of other categories (14) including (doctors, dietitians, coaches, car drivers, traffic policemen) were also cited. Thirtytwo participants said that they could not think about anyone who would approve, because everyone was conscious of how risky that choice would be, while 10 people said that they did not know of any category or group.

\subsubsection{People and categories that would disapprove of participants using a bike in the city}

Family members were mentioned most often (28) as people who would disapprove of the respondent riding a bike. In the majority of cases (25), reasons were linked to its perceived danger, but some also pointed out that the choice of riding a bike instead of, for example, driving a car, could cause inconveniences to everyday family routines, as it would entail substantial reorganisations of the distribution of tasks. Friends and acquaintances (5) were also mentioned as people who would potentially disapprove of such a choice, and even in this case, the main reason was linked to their concern for the respondent's safety.

People at work (colleagues, bosses, customers) were cited as well (17), but with radically different explanations. These ranged from the impossibility of accomplishing the tasks required by one's own job (for example delivering goods, carrying work tools, etc.) to the critique expected from bosses due to inappropriate behaviours and dressing styles that the use of bikes would imply.

With regard to concerned groups or categories, 63 respondents mentioned categories that have economic interests against the use of bikes, such as owners and attendants of filling stations and oil companies (34), producers and sellers of motorised vehicles (15), the bus and subway company and taxi drivers (7).

A particular case involved car owners, pedestrians and truck drivers (cited by 17 participants), who were considered antagonists of cyclists because of their competition for the use of street spaces that an increase in the number of bikes would cause, particularly if no dedicated lanes were pre-arranged. Finally, 13 participants were unable to suggest any category or group.

\section{Conclusion (study 2)}

Most of the participants to study 2 were able to express both positive and negative beliefs about the consequences of using a bike in a big city like Rome, and could mention both social supporters and antagonists of the bike.

With respect to the consequences, they seemed aware of the potential benefits that the use of bikes in urban contexts could have for the environment, urban mobility and one's own wellbeing. However, they also expressed many concerns about the potential risks associated with the use of this means of transportation in a car-centred city like Rome. In other words, while they thought that, in principle, the bike could be a solution for many transport and health issues, its actual implementation in their city remains confined to an implausible future and linked to a radical cultural change that they found was hard to believe in. Some concerns were also expressed in relation to the lifestyle changes that habitual use of the bike would entail. This aspect deserves to be further explored in the future as it indicates that implications other than journey times, lanes availability and distances could also be involved. Given the crucial role that transportation has in modern western societies, respondents were aware that a change in their mode choice (i.e. from cars to bikes) would have inevitable implications for their everyday social, family and work relations and for the role and/or task distribution within all of these social groups. This consequence suggests that social approval from these people might play a role in the decision to adopt the bike as a habitual means of transportation. Indeed, it is plausible that, in many cases, the decision to change one's own daily transport routines is not just a matter of personal choice but of collective decisions as well. It entails the acceptance of a substantial re-organisation of goals, times and tasks at the interpersonal and group level.

Another aspect worth highlighting is the strong association of the beliefs expressed with particular emotional reactions. These emotions are in parallel with the complex nature of the overall representation of bikes. The bike was thus able to elicit feelings of fear and joy, worry and freedom, anxiety and reassurance, unease and calm. Such emotions emerged spontaneously throughout the interviews, no request of talking about their emotions was explicitly made to participants (see for examples extracts of participants P31 and P42, reported in Table 5, and P39 and P49 reported in Table 6). It seems, thus, that these aspects deserve to be further investigated in the future (for recent discussions see Gatersleben \& Uzzel, 2007; Passafaro et al., 2014).

Another aspect worth noticing concerns the differences between bikers and non-bikers. Although this study did not aim at assessing inter-individual differences in the contents of the beliefs recorded, we had the impression that bikers had a more positive view of the use of bikes in the city than non-bikers, as many bikers (4) were unable to report any negative aspects at all. This is reasonable and congruent with previous findings (Gatersleben \& Uzzel, 2007) and would suggest, once more, the importance of comparing the views of bikers and non-bikers, as this might help in setting up specific promotional campaigns for the two target groups (see also Gatersleben \& Appleton, 2007).

\section{General discussion}

The studies discussed herein indicate that a relationship might exist between the way in which the mass media address certain urban travel issues and people's beliefs regarding these same issues. As one's beliefs have proven to play a crucial role 
in affecting the individual's behaviour, it is evident that more studies should be devoted to deepening the understanding of this relationship. In this specific case, the results showed that, consistent with the Agenda Setting Theory, the representation of the bike as it emerges from the mass media in Italy has many points of overlap with its representation emerging from people who live in a big city such as Rome. In particular, the two representations share the main idea that riding a bike is risky and dangerous, though it could be healthy, fun and sustainable. Both representations also share the notion that, at present, the negative implications of the use of bikes in a big city override the positive benefits so that the bike seems to embody the dream of a sustainable city of the future rather than a concrete solution to the urban problems at present. However, a few differences were also noted, some of which can be explained with the different nature of the units of analysis considered. For example, commercial advertisements tend in general to avoid fear arousing appeals and prefer to frame their messages within reassuring positive contexts. It is thus less likely that negative messages (accidents, theft, assaults, etc.) appear within this kind of units of analysis. On the contrary, crime events tend to be reported more often by press news as they are more informative and appealing to the readers. People tend instead to have a more articulated perspective on this topic than the media. For example, an aspect that was only marginally addressed by the media concerned the implications of changing transport habits on the social relationships within the family, work and peer environments. In other words, mass media tended to address consequences at the personal (danger vs. well-being) and social (urban mobility and sustainability) levels, whereas a discussion of the possible outcomes of such change at the interpersonal level was lacking. This level involves aspects such as social identity, social roles and group norms, which might play a crucial role in people's decisions regarding their transport mode choice, as they have already proven to be among the most direct determinants of individual behaviour in general (Ajzen, 1991; Fishbein \& Ajzen, 2010). The fact that the media considered here did not mention this specific problem might have various explanations. For example, mass media communication concerning the bike in Italy might mirror a general lack of public policies, systematic analysis, and specific strategies to promote the use of bike. In absence of a thorough investigation of this phenomenon by decision-makers, they rely upon common sense ideas (doctors have often repeated that bike is an health enhancing means of transportation, as well as ecologists and scientists constantly repeat that they are environmentally sustainable) and upon evidences from everyday news reporting accidents and assaults. A deeper analysis of the way in which travel mode choice can affect people's lifestyle at the inter-individual level would set media agenda more in line with citizens' representations of this phenomenon.

Another aspect that was mentioned by respondents concerned the social supporters and antagonists of bike use. The participants in this study were aware of the many economic interests involved in urban mobility issues. Such aspects were only marginally addressed by the media considered here, although they may play a crucial role in political decision-making and may represent substantial obstacles (or incentives) to the diffusion of more sustainable mobility options in urban contexts worldwide. Finally, although safety and security were prominent and recurrent themes in both the media's and people's representations of the bike, the possible ways of solving this problem were only marginally addressed in the discourses that were analysed in this study, and almost exclusively in relation to the availability of cycling facilities. Cyclists' responsibilities to adopt appropriate behaviours and wear the necessary safety gear were almost neglected in both cases. Nevertheless, these represent crucial aspects of actual and perceived safety in cycling, and the mass media could play a key role in improving them both.

More generally, the findings discussed herein suggest that combining information from mass media and the general public could be helpful to designing appropriate strategies for both interventions and communications directed towards prompting specific desired behaviours, attitudes or lifestyles within general and/or particular targets of a given urban population.

\subsection{Limits of the study}

A limit of this study is that the sampling procedure for the mass media analysis was aimed at ensuring that there was a variety of contents and not the overall coverage of the topic addressed in a given period. Identifying the variety of contents is a crucial step when studying an issue for which no previous data are available. This is because it may help in formulating specific hypotheses, identifying particular targets and providing cues on how to build the necessary measurement instruments, which were the aims of the present study. However, future studies should also assess the overall coverage of the topics identified throughout the media, because it would be more informative for understanding the relative impact of these topics on the public. Moreover, as the authors received no funds to support the study, time sampling was guided by convenience criteria. This might have affected the results of study 1 , because it is possible that if different periods of the years had been sampled, other aspects would have emerged. Future studies focused on longer periods laps (such as the one recently conducted by Sarrica et al., 2014, on energy use) could better grasp content characteristics of the representation of bike and their evolution over time.

Similarly, there is no way to assess the extent to which the ideas expressed by the participants to study 2 are shared by Rome's citizens in general. Moreover, most of the respondents in study 2 declared that they did not use a bike habitually, which might have altered the results by leading to an overrepresentation of negative beliefs over positive ones. Also, the pervasive perception that using a bike for daily transport necessities is somehow utopian at the moment could be linked to this sample bias. Previous studies have shown that cyclists clearly tend to have more positive views of the usefulness of bikes for themselves and their communities and a more optimistic view of its future diffusion (Gatersleben \& Appleton, 2007). However, although the few cyclists interviewed here were undoubtedly more positive towards the use of bikes in the city, they 
nevertheless expressed many concerns and admitted, as did the others, that a lack of social and political support (lack of lanes, drivers' hostility, conflicting economic interest) exist in this city that renders their choice quite heroic.

Another limit of this study is the focus on the image of bikes without distinguishing it from the image of cyclists. Previous research has suggested that the two representations might differ, with "bikes" receiving more positive connotations than "cyclists" (Rissel et al., 2010). More generally, it seems that when discourses are framed in terms of actors or users rather than in terms of the means that is used, insider/outsider relationships tend to be evoked which are then used to make sense of the events discussed. For example, McCarthy (2011) found that habitual cyclists accused drivers of holding an anti-cycling culture and of treating them as outsiders who do not belong on the road. Such anti-cycling culture and the behaviour associated with it were in turn considered as the cause of the risks of riding a bike. Indeed, some participants of study 2 suggested similar ideas when they referred to the disrespectful and also aggressive behaviour of drivers, who typically appear annoyed by the presence of cyclists on the road. Such behaviour was in turn considered as a cause of the danger of riding a bike in the city, and a point against its actual use. Hence, there are cues that cyclists might be considered as invaders who compete with drivers for the same spatial areas, thus evoking in-group/out-group dynamics, reasoning and, possibly, behaviours.

\section{Appendix A. Interview schedule}

Interviews opened with the following three statements that needed to be completed by participants and which aimed at measuring behavioural beliefs:

(1) "I would use more often the bike for my travel necessities in this city if. .."

(2) "Using the bicycle more often for my travel necessities in this city would be good for me, because...."

(3) "Using the bicycle more often for my travel necessities in this city would be a problem for me, because..."

Participants were subsequently asked the following 4 questions aimed at investigating their normative beliefs:

(4) If you used the bicycle more often for your travel necessities in this city, who do you think would approve you? Why?

(5) If you used the bicycle more often for your daily travel necessities in this city, who do you think would disapprove you? Why

(6) Could you think about any social group or category who would approve you, if you used the bike for your daily travel necessities in this city? Why?

(7) Could you think about any social group or category who would disapprove you, if you used the bike for your daily travel necessities in this city? Why?

Interviewers were given specific instructions on how to change the statements of all the items when interviewing participants who had declared to already use the bike regularly. For example, they were instructed to skip item 1 and to change item 2 into "Using the bicycle regularly for my travel necessities is good for me, because. ..". All other items had to be changed accordingly.

\section{References}

Ader, C. R. (1995). A longitudinal study of agenda setting for the issue of environmental pollution. Journalism E Mass Communication Quarterly, 72, 300-311.

Ajzen, I. (1991). The theory of planned behaviour. Organizational Behaviour and Human Decision Processes, 50, $179-211$.

Andrews, K. T., \& Caren, N. (2010). Making the news: Movement organizations, media attention and the public agenda. American Sociological Review, 75(6), $841-866$.

Atkin, C. K. (1980). Effects of the mass-media. New York: McGraw-Hill.

Becker, B. W., \& Connor, P. E. (1981). Personal values and the heavy user of Mass Media. Journal of Advertising Research, 21 (5), 37-43.

Benton, M., \& Frazier, P. J. (1976). The agenda setting function of the mass media at three levels of 'Information Holding'. Communication Research, 3(3), $261-274$.

Berelson, B. (1952). Content analysis in communication research. New York: The Free Press.

Bjerregaard, R. (1999). Foreword to J. Dekoster and U. Schollaert cycling: The way ahead for towns and cities. European Commission DG IX, Environment, Nuclear, Safety and Civil Protection Belgium.

Brondi, S., Armenti, A., Cottone, P., Mazzare, B. M., \& Sarrica, M. (2014). Parliamentary and press discourses on sustainable energy in Italy: No more hard paths, not yet soft paths. Energy Research and Social Science, 2, 38-48.

Curtin, P. A., \& Rhodenbaugh, E. (2001). Building the news media agenda on the environment: A comparison of public relations and journalistic sources. Public Relations Review, 27, 179-195.

Denham, B. E. (2004). Toward an explication of media enjoyment: The synergy of social norms, viewing situations and program content. Communication Theory, 14(4), 370-387.

Eagly, A., \& Chaiken, S. (1993). The psychology of attitudes. New York: Hartcourt Brace Jovanovich.

Fearing, F. (1953). Towards a psychological theory of human communication. Journal of Personality, 22, 71-88.

Fishbein, M., \& Ajzen, I. (2010). Predicting and changing behavior: The reasoned action approach. New York: Psychology Press.

Gandy, O. (1982). Beyond agenda setting: Information subsidies and public policies. Norwood, NJ: Ablex Publishing Company.

Gatersleben, B., \& Appleton, K. (2007). Contemplating cycling to work: Attitudes and perceptions in different stages of change. Transportation Research Part A: Policy and Practice, 41, 302-312.

Gatersleben, B., \& Uzzel, D. (2007). Affective appraisal of the daily commute: Comparing perceptions of drivers, cyclists, walkers and users of public transport. Environment and Behavior, 39, 416-431.

Glaser, B., \& Strauss, A. L. (1967). The discovery of grounded theory: Strategies for qualitative research. Chicago: Aldine. 
Holbert, R. L., Kwak, N., \& Shah, D. V. (2003). Environmental concern, patterns of television viewing, and pro-environmental behaviors: Integrating models of media consumption and effects. Journal of Broadcasting E Electronic Media, 47(2), 177-196.

Holsti, O. R. (1969). Content analysis for the social sciences and humanities. Reading, Mass.: Addison-Wesley.

Jovchelovitch, S. (2001). Social representations, public life and social construction. In K. Deaux \& G. Philogene (Eds.), Representations of the social: Bridging theoretical traditions (pp. 165-182). Oxford: Blackwell Publishing.

Kassarjian, H. H. (1977). Content analysis in consumer research. Journal of Consumer Research, 4(1), 8-18.

Kitzinger, J. (2007). Framing and frame analysis. In E. Devereux (Ed.), Media studies: Key issues and debates (pp. 134-161). London, UK: Sage.

Krippendorff, K. (1980). Content analysis: An introduction to its methodology. London: Sage.

Livingstone, S. M. (1990). Making sense of television. The psychology of audience interpretation. Oxford: Pergamon Press (2nd ed., 1998).

Losito, G. (2009). The analysis of media consumption: The active role of the 'audience'. REM, 1(1), 121-131.

McCarthy, D. (2011). I'm a normal person: An examination of how utilitarian cyclists in Charleston South Carolina use and insider/outsider framework to make sense of risks. Urban Studies, 48, 1439-1455.

McCombs, M. (2005). A look at agenda-setting: Past, present and future. Journalism Studies, 4, 543-557.

McCombs, M. E., \& Shaw, D. L. (1972). The agenda-setting function of the press. Public Opinion Quarterly, 36, $176-187$.

Moscovici, S. (2001). Why a theory of social representations? In K. Deaux \& G. Philogène (Eds.), Representations of the social: Bridging theoretical traditions (pp. 8-35). Malden: Blackwell Publishing.

Passafaro, P., Rimano, A., Piccini, M. P., Metastasio, R., Gambardella, V., Gullace, G., et al (2014). The bicycle and the city: Desires and emotions vs attitudes, habits and norms. Journal of Environmental Psychology, 38, 76-83.

Rissel, C., Bonfiglioli, C., Emilsen, A., \& Smith, B. J. (2010). Representations of cycling in metropolitan newspapers - Changes over time and differences between Sydney and Melbourne. Australia, BMC: Public Health. http://dx.doi.org/10.1186/1471-2458-10-371.

Sarrica, M., Brondi, S., \& Cottone, P. (2014). Italian views on sustainable energy: Trends in the representations of energy, energy system, and user, 20092011. Nature and Culture, 9, 122-145.

Schwartz, S. H. (1992). Universals in the content and structure of human values: Theoretical advances and empirical tests in 20 countries. Advances in Experimental Social Psychology, 25, 1-66.

Shaw, E. F. (1979). Agenda setting and mass communication theory. Gazette, 2, 96-105.

Stern, P. C., Dietz, T., \& Guagnano, G. A. (1998). A brief inventory of values. Educational and Psychological Measurement, 58, $984-1001$.

Strauss, A. L., \& Corbin, J. M. (1990). Basics of qualitative research: Techniques and procedures for developing grounded theory. London: Sage.

Turk, J. V. (1986). Public relations' influence on the news. Newspaper Research Journal, 7, 15-27.

Zaho, X. (2012). Personal values and environmental concern in China and the US: The mediating role of informational media use. Communication Monographs, 79(2), 137-159. 